\title{
Effect of Composite Patch Geometry in Notched Plates Under Low Velocity Impact
}

\begin{tabular}{|c|c|}
\hline \multicolumn{2}{|c|}{ Umut ÇALIŞKAN $^{* 1}$, Recep EKİCi ${ }^{1}$, Mustafa Kemal APALAK ${ }^{1}$} \\
\hline \multicolumn{2}{|c|}{${ }^{1}$ Erciyes University, Faculty of Engineering, Kayseri, TURKEY } \\
\hline \\
\hline Başvuru/Received: $08 / 10 / 2017 \quad$ Kabul/Accepted: $01 / 12 / 2017 \quad$ Son Versiyon/Final Version: $26 / 12 / 2017$ \\
\hline
\end{tabular}

\begin{abstract}
The repair technique of the composite patch with bonding adhesive are used with the purpose of repairing materials and increasing working life of the materials. In this study, the impact strength of notched metal materials repaired by composite patch investigated by numerically. Fiber reinforced laminated composite patch was modeled by using finite element model. Composite patch was bonded to damaged materials, and this structure was subjected to impact test. The geometrical and material non-linearities were considered in the explicit dynamic analysis. The notched plate was made of aluminum 6061-T6. The effects of design parameters, such as composite patch geometry, on the impact energy absorption of the plates were investigated. The metal notched plates were modeled as a Johnson-Cook material model and the composite patches were modeled orthotropic elastic material model and Hashin damage. In the analysis results, the damage mechanisms of composite patch were exhibited and strength of damaged materials was exhibited in terms of contact force, kinetic energy and stress distributions. The effect of patch geometries was also investigated in terms of absorbing impact energies. As the plates without patch perforated, repaired metal notched plates with composite patch did not perforate.
\end{abstract}

\section{Key Words}

"Composite Patch, Notched Materials, Impact, Non-linear Finite Element Method." 
the prediction of the initiation and propagation of the damages in the composite materials needs various damage models to be considered.

The other important subject is that the occuring damages at the composite and metal materials repair. The repair technique of the composite patch with bonding adhesive are used with the purpose of repairing materials and increasing working life of the materials. The damages in different size occur at the nose cone of the air crafts, cockpit glasses, the outside of the aerofoils, horizontal and vertical stabilizator because of extrinsic factors such as birds, hail, lightning, impact vehicles on the ground. The damage in different size occur again at the car bumper and hood cause of the crashing other cars and objects. Different repair technique and patch are used to prevent damage progression, increasing static and fatigue strength again, increasing the working life. The determining other issues are that choosing the suitable patch for the damaged materials, measuring the strength of the damaged materials after applying the patch. Mall and Conley (2009) presented a crack growth behavior of cracked panels repaired with bonded composite patch using a two-dimensional finite element analysis. Their experimental tests about fatigue were carried out precracked aluminum specimens of two thicknesses $(1$ and $6.35 \mathrm{~mm}$ ), with and without debond, and repaired asymmetrically. Four and ten times relative to unrepaired cases were extended fatigue lives of thick and thin repaired panels, respectively. Their experimental values at the unpatched face were in good agreement the predicted fatigue crack growth rates but not at the patched face. Thus, the present analysis provided a conservative assessment of durability and damage tolerance of repaired thin and thick panels. Shams and El-Hajjar (2013) studied on the overlay repair of scratch damage in carbon- fiber/epoxy composite laminates numerically and experimentally. The scratch damage severed several load bearing plies and results in a lack of symmetry in an originally symmetric multidirectional laminate. The effects of the repair patch variables on the overall efficiency of the repair procedure and the lamina level stress states were investigated using the ply-by-ply p-version finite element model. Their results showed that interlaminar crack propagation in the direction parallel to the surface kept back with careful selection of repair parameters. Albedah et al. (2016) investigated the fatigue behavior of aluminum alloy $2024 \mathrm{~T} 3 \mathrm{v}$-notched specimens repaired with composite patch under block loading experimentally. Two different loading blocks were applied as increasing and decreasing at two stress ratio: $\mathrm{R}=0$ and $\mathrm{R}=0.1$. Their damaged specimens were observed using scanning electron microscope at different magnifications to analyze their fractured surfaces. The results showed that the crack growth is accelerated for both repaired and unrepaired specimens. Cheng et al. (2014) studied notched composite plates repaired with external circular patches. In the case of a strong adhesive joint, the stiffness of the patches had to be optimized to release high stress concentration and obtained the best repair performance. Their results showed that the damage progression of the repairs depended not only on the patch stiffness but also on the stacking sequence. Constantin et al. (2013) presented a behaviour of repaired Al panels which are bonded composite repair patches under lateral pressure loads for the different geometries and materials. Their finite element models were validated by experiments in a number of cases, and then used to evaluate the whole proposed range of repair patching configurations. Errouane et al. (2014) investigated a composite patch repair aluminum plate consisting a central crack for the optimization. The patch was bonded over a cracked aluminum sheet using a small adhesive layer placed in between. The numerical model allowed to predict the patch effect on the behavior of the cracked plate under tensile loading. Several stacking sequences and material properties were also investigated to reduce the stress concentration in the vicinity of the crack tip, leading to strong volume reduction. Benyahia et al. (2015) studied the behaviour of aged bonded composite repair of aircraft structures experimentally and numerically. The accelerating aging of the patch was realized by immersion in water for 120 days. Their experimental results showed that the fatigue life of the aircraft structures could be significantly improved with the patch repair. The patch aging reduced the repair performances because of the reduction of the composite rigidity by humidity absorption. Sabelkin et al. (2007) studied several parameters/factors for the mechanical and fatigue behaviors of a cracked 7075-T6 aluminum panel repaired with one-sided adhesively bonded composite patch by experimentally and analytically. The effects of cool-down temperature during patch bonding were also investigated. Residual thermal stresses, developed during patch bonding, requires the knowledge of temperature at which adhesive becomes effective in creating a bond between the specimen and patch. The bonded patch repair of a cracked panel provides a considerable increase in the residual strength as well as fatigue life. 
This paper aims to investigate the low velocity impact response of repaired notched plates with composite patches and the effects of composite patch geometry for the various impact energies. ABAQUS/Explicit was used to predict the dynamic response of repaired notched plates. A special care was paid for the behavior of impacted regions and composite patches geometry.

\section{Finite element model}

The low velocity impact behavior of notched plates was studied using ABAQUS/Explicit (version 6.14)(ABAQUS/Explicit). The impact behavior was investigated for different composite patch geometry under three impact energy levels of 50,100 and $150 \mathrm{~J}$. Notched metal plate was in dimension of 100x100 mm and its thickness was taken as $2 \mathrm{~mm}$. Notch geometry was in dimenson of 1x1 x30 mm.

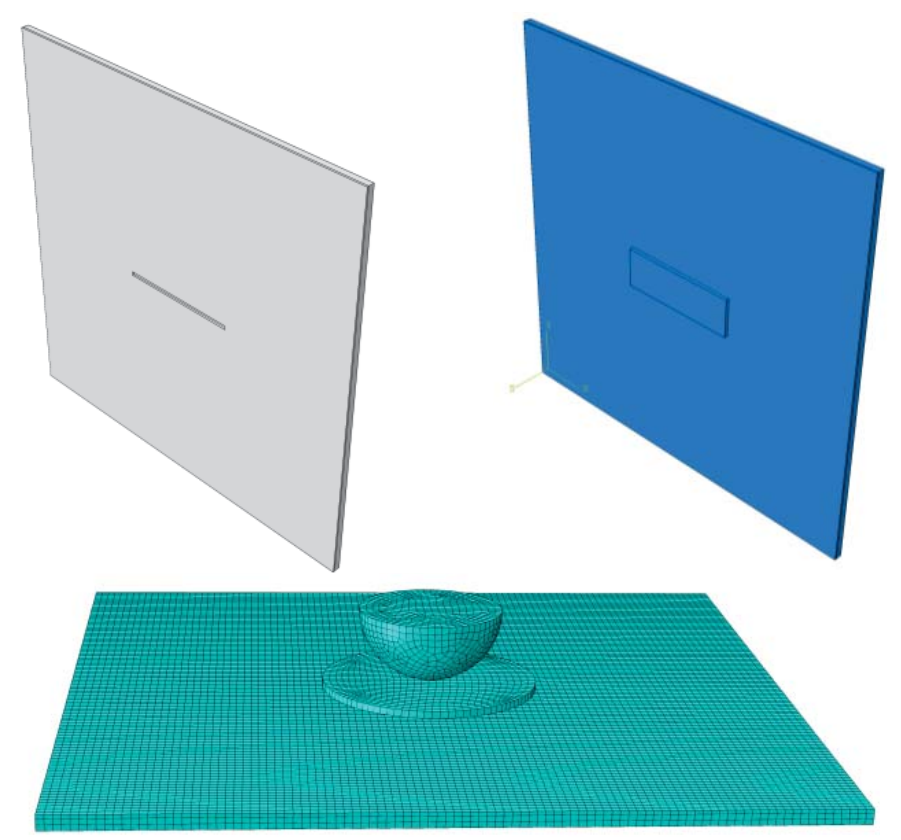

Figure 1. Finite element model

Two different types patch geometries were used as circular and rectangular. Circular composite patch radius was in dimension of $15 \mathrm{~mm}$ and thickness of $1 \mathrm{~mm}$. The rectangular composite patch geometry was in dimension 1x10x30 $\mathrm{mm}$. Damaged metal with notched, circuler and rectangular composite patch models were shown in Figure 1. The stress and strain curve of notched metal plate of AA6061-T6 was shown in Figure 2.

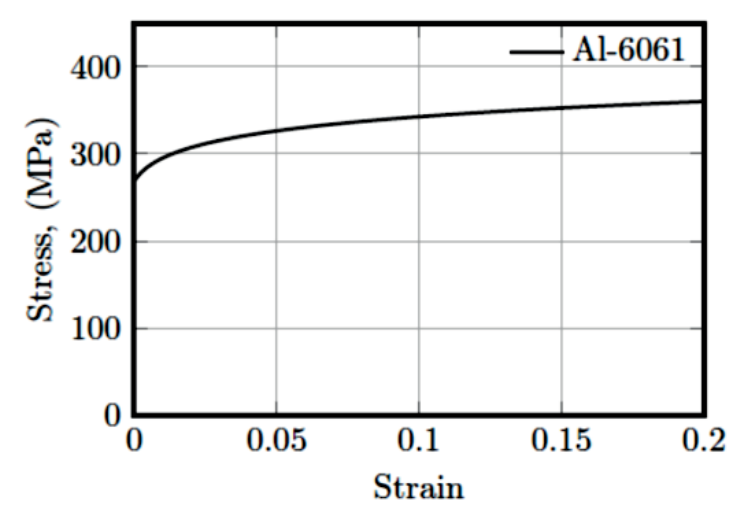

Figure 2. Stress-Strain curve of AA 6061 - T6. 
The non-linear behaviour of face-sheets materials was modeled using Johnson-Cook material model. The Johnson-Cook dynamic failure model is used as a specific case of the ductile damage initiation criterion for metals in ABAQUS/Explicit. The important parameneters used in Johnson-Cook dynamic failure model were given in Table 1 for aluminum $6061 \mathrm{~T} 6$.

Table 1. Constants for Johnson-Cook dynamic failure model of Aluminum Al6061 T6

\begin{tabular}{lc}
\hline Aluminum $6061 \mathrm{~T} 6$ & Johnson-Cook Model \\
\hline$\rho(\mathrm{kg} / \mathrm{m} \mathrm{3})$ & 2700 \\
$E(\mathrm{GPa})$ & 70 \\
$v$ & 0.33 \\
$C_{p}(\mathrm{~J} / \mathrm{kgK})$ & 910 \\
$\alpha\left(\mathrm{K}^{-1}\right)$ & $2.30 \times 10^{-5}$ \\
$\dot{\varepsilon}\left(\mathrm{s}^{-1}\right)$ & 597.2 \\
$A(\mathrm{MPa})$ & 270 \\
$B(\mathrm{MPa})$ & 154.3 \\
$C$ & 0.1301 \\
$n$ & 0.2215 \\
$m$ & 1.34 \\
$T_{f}(\mathrm{~K})$ & 925 \\
$d_{1}$ & -0.77 \\
$d_{2}$ & 1.45 \\
$d_{3}$ & 0.47 \\
$d_{4}$ & 0.0 \\
$d_{5}$ & 1.6 \\
\hline
\end{tabular}

The impactor was modeled as a rigid body behavior. The encastered boundary condition was applied to the model. Composite patches were modelled using a continuum shell element with 8-node hexahedron (SC8R). The mechanical contact between the impactor and plate was simulated by the GENERAL CONTACT ALGORITHM in Abaqus/Explicit. Composite patches were modelled as four layer and unidirectional laminate fiber angle of 0。(Fig. 2). The material damage initiation capability for fiber-reinforced materials requires that the behavior of the undamaged material is linearly elastic, is based on Hashin's theory and can be used in combination with the damage evolution model described in "Damage evolution and element removal for fiber-reinforced composites" in the Abaqus/Explicit code.

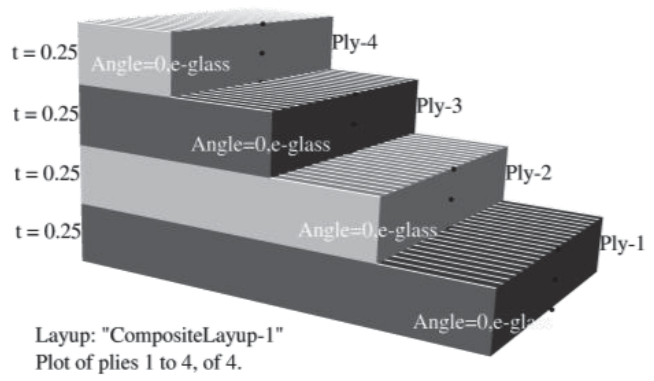

Figure 2. Py orientation of fiber composite patch

Damage initiation refers to the onset of degradation at a material point. In Abaqus the damage initiation criteria for fiber-reinforced composites are based on Hashin's theory. These criteria consider four different damage initiation mechanisms: fiber tension, fiber compression, matrix tension, and matrix compression and mechanical properties for the composite plates E-glass/epoxy are given in Table 2 (Singh et al. (2015)). 
Table 2. Elastic and strength properties for composite patch

\begin{tabular}{ll}
\hline Longitudinal modulus, $E_{11}$ & $40(\mathrm{GPa})$ \\
Transverse modulus, $E_{22}=E_{33}$ & $10(\mathrm{GPa})$ \\
Shear modulus, $G_{22}=G_{33}$ & $3.15(\mathrm{GPa})$ \\
Shear modulus, $G_{23}$ & $4.32(\mathrm{GPa})$ \\
Volume fraction of fiber, $V_{f}$ & 0.54 \\
Poisson's ratio, $\mu_{12}=\mu_{13}$ & 0.3 \\
Poisson's ratio, $\mu_{23}$ & 0.21 \\
Density & $1780\left(\mathrm{~kg} / \mathrm{m}^{3}\right)$ \\
Longitudinal tensile strength, $X_{T}$ & $988(\mathrm{MPa})$ \\
Transverse tensile strength, $Y_{T}=Z_{T}$ & $44(\mathrm{MPa})$ \\
Longitudinal compressive strength, $X_{C}$ & $1432(\mathrm{MPa})$ \\
Transverse compressive strength, $Y_{C}=Z_{C}$ & $285(\mathrm{MPa})$ \\
In-plane shear strength $S_{12}=S_{13}$ & $60.6(\mathrm{MPa})$ \\
Interlaminar shear strength, $S_{23}$ & $22(\mathrm{MPa})$ \\
\hline
\end{tabular}

The initiation criteria have the following general forms:

Fiber tension $\left(\widehat{\sigma_{11}} \geq 0\right)$

$F_{f}^{t}=\left(\frac{\widehat{\sigma_{11}}}{X^{T}}\right)^{2}+\alpha\left(\frac{\widehat{\tau_{12}}}{S^{L}}\right)^{2}$

Fiber compression $\left(\widehat{\sigma_{11}}<0\right)$

$F_{f}^{c}=\left(\frac{\widehat{\sigma_{11}}}{X^{C}}\right)^{2}$

Matrix tension $\left(\widehat{\sigma_{22}} \geq 0\right)$

$$
F_{m}^{t}=\left(\frac{\widehat{\sigma_{22}}}{Y^{T}}\right)^{2}+\alpha\left(\frac{\widehat{\tau_{12}}}{S^{L}}\right)^{2}
$$

Matrix compression $\left(\widehat{\sigma_{22}}<0\right)$

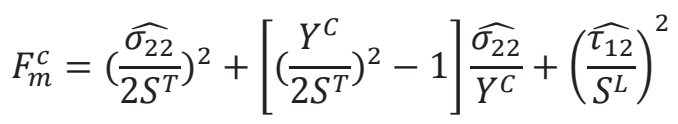

$\widehat{\sigma_{11}}, \widehat{\sigma_{22}}, \widehat{\tau_{12}}$ are components of the effective stress tensor, $\hat{\sigma}$, that is used to evaluate the initiation criteria and which is computed from:

$\hat{\sigma}=M \sigma$

Where $\sigma$ is the true stress and is the damage operator:

$$
M=\begin{array}{ccc}
\frac{1}{\left(1-d_{f}\right)} & 0 & 0 \\
0 & \frac{1}{\left(1-d_{m}\right)} & 0 \\
0 & 0 & \left.\frac{1}{\left(1-d_{s}\right)}\right\rfloor
\end{array}
$$

$d_{f}, d_{m}$, and $d_{s}$ are internal (damage) variables that characterize fiber, matrix, and shear damage, which are derived from damage variables, $d_{f}^{t}, d_{f}^{c}$, and,$d_{m}^{c}$ corresponding to the four modes previously discussed, as follows :

$$
d_{f}= \begin{cases}d_{f}^{t} & \text { if } \widehat{\sigma_{11}} \geq 0 \\ d_{f}^{c} & \text { if } \widehat{\sigma_{11}}<0\end{cases}
$$




$$
\begin{aligned}
& d_{m}=\left\{\begin{array}{lll}
d_{m}^{t} & \text { if } \widehat{\sigma_{22}} \geq 0 \\
d_{m}^{c} & \text { if } \widehat{\sigma_{22}}<0
\end{array}\right. \\
& d_{s}=1-\left(1-d_{f}^{t}\right)\left(1-d_{f}^{c}\right)\left(1-d_{m}^{t}\right)\left(1-d_{m}^{c}\right)
\end{aligned}
$$

\section{Results}

Impact analyses were performed for impact energies of 50,100 and $150 \mathrm{~J}$, respectively. The impactor was spheral tip geometry of $20 \mathrm{~mm}$ in diameter, and $5.045 \mathrm{~kg}$ of a mass. The geometrical design parameter of composite patch geometry was investigated to improve the impact energy absorption capability of the structure and avoid damage. The temporal variations of the contact force and kinetic energy were determined for three impact energy levels of 50, 100 and $150 \mathrm{~J}$, respectively. Two different types of composite patch geometry were used for repairing notched metal plate as circular and rectangular. Impact analyses were also performed for without patch for three energy levels. These three situations were compared in terms of contact force histories, kinetic energy levels and stress distributions on the notched metal plate of AA6061 - T6. E-glass/epoxy (UD) was used for composite patch material and thickness of 1 mm (4 layer).

Figure 3 shows the effect of composite patch geometry on the temporal variations of the contact force and kinetic energy histories for three impact energy levels, respectively. The peak contact forces are measured as 11.92, 14.29 and $13.81 \mathrm{kN}$ under the impact energy level of $50 \mathrm{~J}$ notched plate without patch, with circular patch and with rectangular patch, respectively, and the corresponding peak contact times are nearly similar for all specimens in about $3 \mathrm{~ms}$. The impact analyses are completed in the total contact times of 4.5, 4.2 and $4.3 \mathrm{~ms}$. The peak contact forces are measured as 13.75, 22.91 and $19.53 \mathrm{kN}$ under the impact energy level of $100 \mathrm{~J}$ notched plate wihout patch, with circular patch and with rectangular patch, respectively, and the corresponding peak contact times are nearly similar for all specimens in about $2.5 \mathrm{~ms}$. The impact analyses are completed in the total contact times of 4.62, 3.76 and 3.86 ms. The peak contact forces are measured as $13.75,31.47$ and $21.63 \mathrm{kN}$ under the impact energy level of $150 \mathrm{~J}$ notched plate, circular patch and rectangular patch, respectively, and the corresponding peak contact times are nearly similar for all specimens in about $2 \mathrm{~ms}$. The impact analyses are completed in the total contact times of 7.02, 3.58 and 43.78 $\mathrm{ms}$. As the impact energy is increased, the peak contact force levels are increased and the total contact durations are decreased for notched metal with circular and rectangular patch. However, the notched metal plate without patch is perforated in the impact energies of 100 and $150 \mathrm{~J}$. The minimum peak contact force appeared in notched metal plate without patch and the maximum peak contact force was appeared in circular patch geometry model.

The notched metal plate without patch, with circular patch and with rectangular patch reduce impact energy of $50 \mathrm{~J}$ to kinetic energy levels of 8.36, 11.20 and $10.54 \mathrm{~J}$, respectively; thus, the impact energies are dissipated by 83.28, 77.6 and $79.2 \%$, respectively. For the impact energy level of $100 \mathrm{~J}$ the models reduce to kinetic energy levels of $6.75,14.65$ and $13.23 \mathrm{~J}$, respectively and the impact energies are dissipated by $93.25,85.35$ and $86.77 \%$, respectively. They also reduce impact energy of $150 \mathrm{~J}$ to kinetic energy levels of 3.03, 16.9 and $12.97 \mathrm{~J}$, respectively; thus, the impact energies are dissipated by $96.97,83.1$ and $87.03 \%$, respectively. The notched metal without patch could absorb more much impact energy, however these plates were perforated in the impact energy levels of 100 and $150 \mathrm{~J}$. 

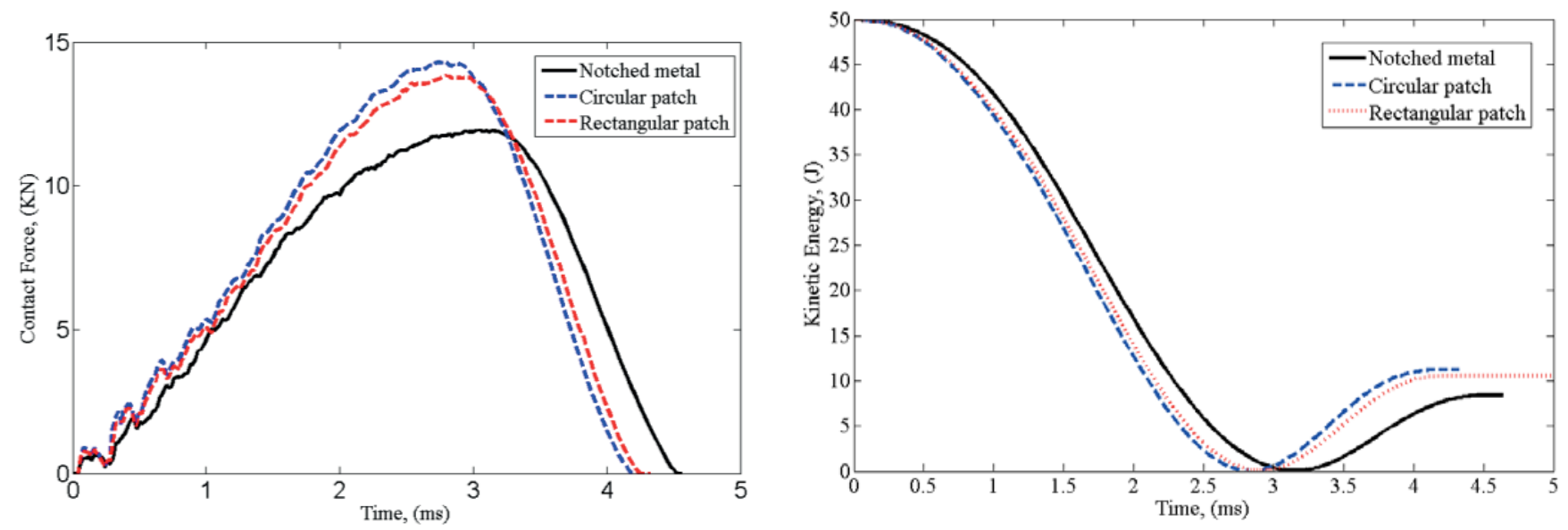

$\mathrm{E}=50 \mathrm{~J}$
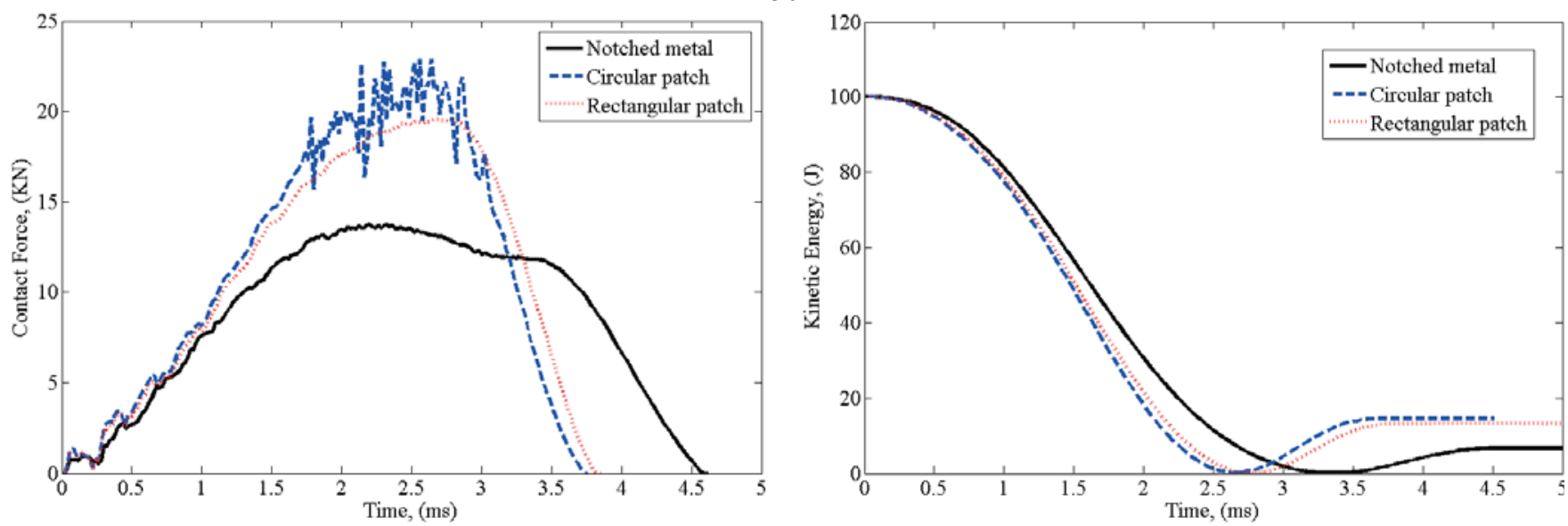

$\mathrm{E}=100 \mathrm{~J}$
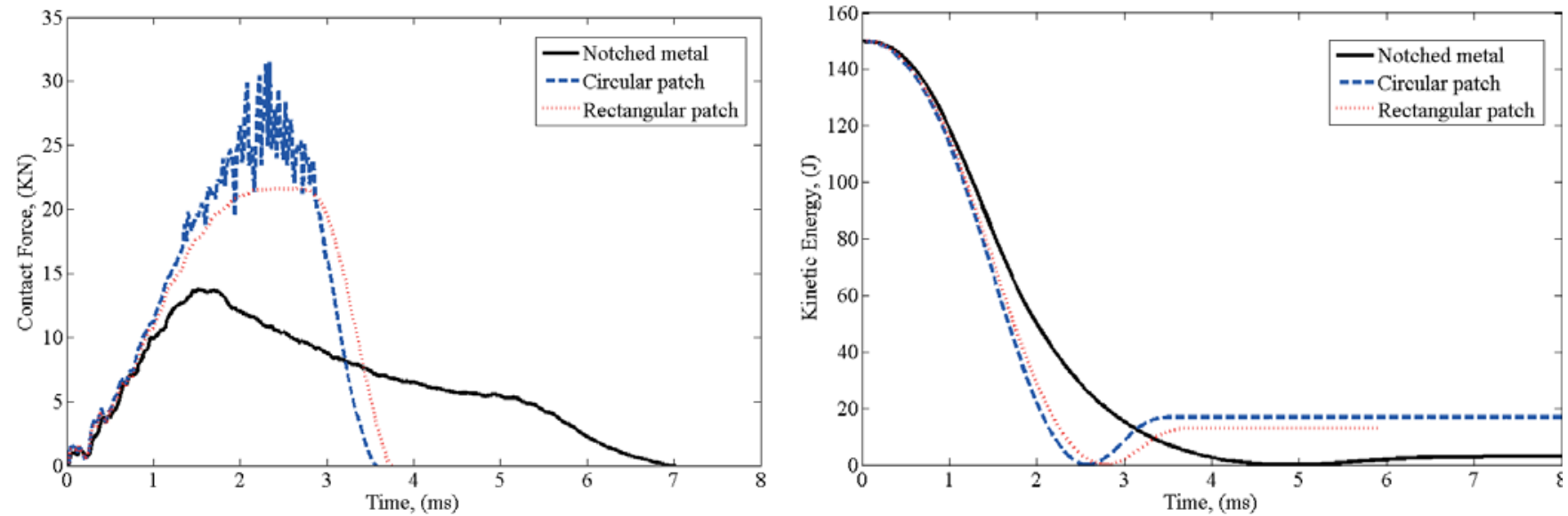

$\mathrm{E}=150 \mathrm{~J}$

Figure 3. Effect of the composite patch geometry on the variations of contact force and kinetic energy for the impact energies of 50, 100 and $150 \mathrm{~J}$.

Figure 4 shows the stress distributions of the notched plate without patch for the impact energy levels of 50, 100 and $150 \mathrm{~J}$. As the impact energy is increased, the stress levels increase naturally. The maximum von-misses stress levels for the impact energy levels of 50,100 and $150 \mathrm{~J}$ are 344, 358 and $403 \mathrm{MPa}$, respectively. The results showed that, If the composite patch is not used, plate can be perforated under impact energy levels of 100 and $150 \mathrm{~J}$. 

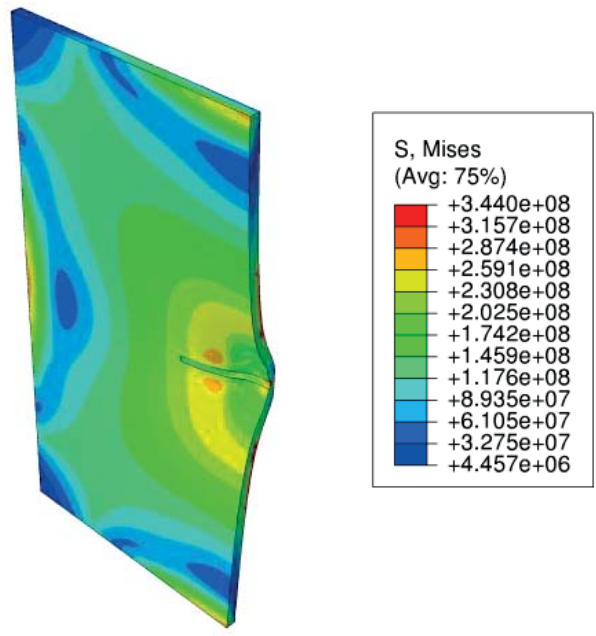

a) $\mathrm{E}=50 \mathrm{~J}$
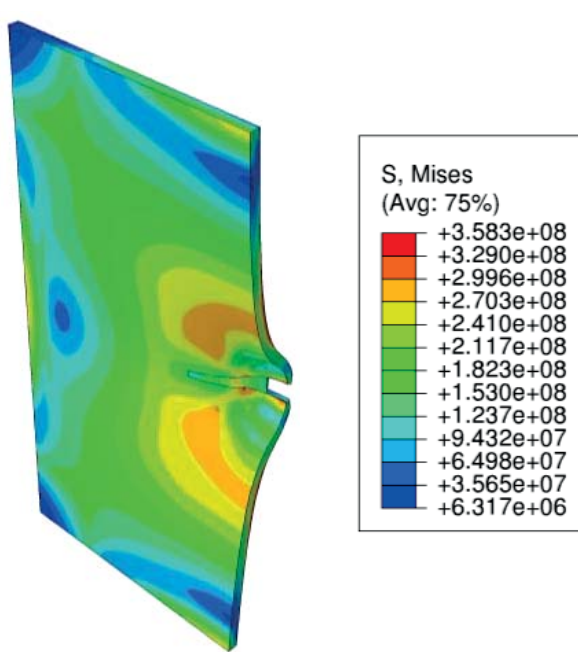

b) $E=100 \mathrm{~J}$
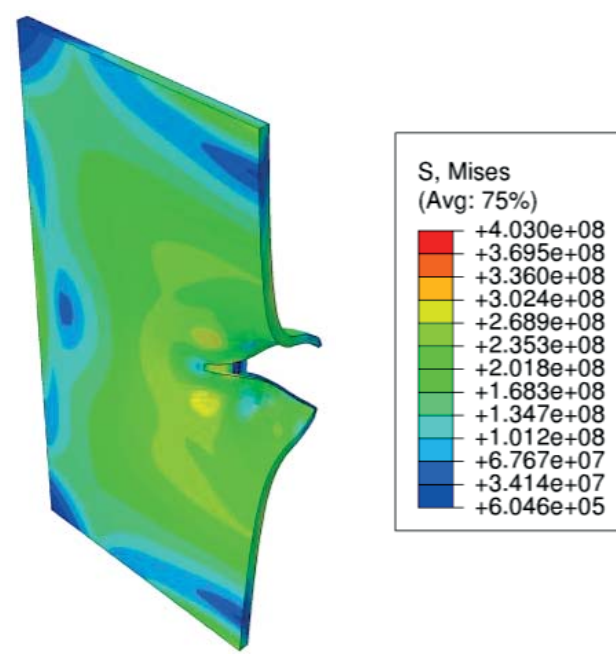

c) $\mathrm{E}=150 \mathrm{~J}$

Figure 4. The effect the impact energy level on the stress distribution of the notched metal plate without patch. 

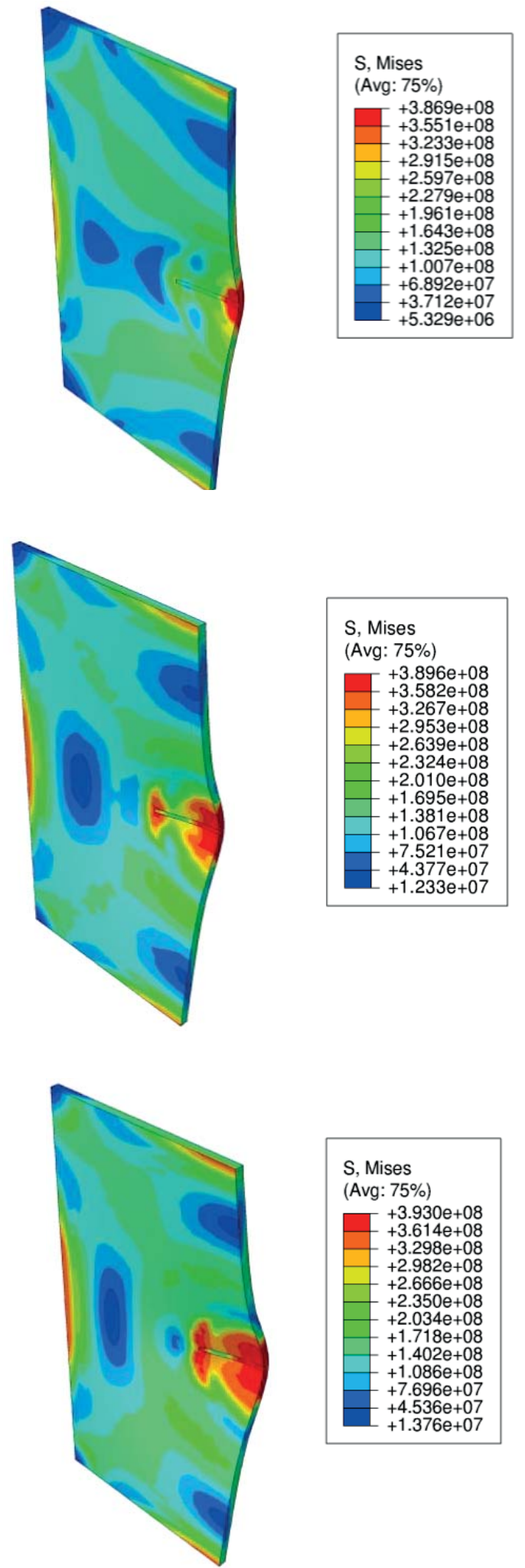
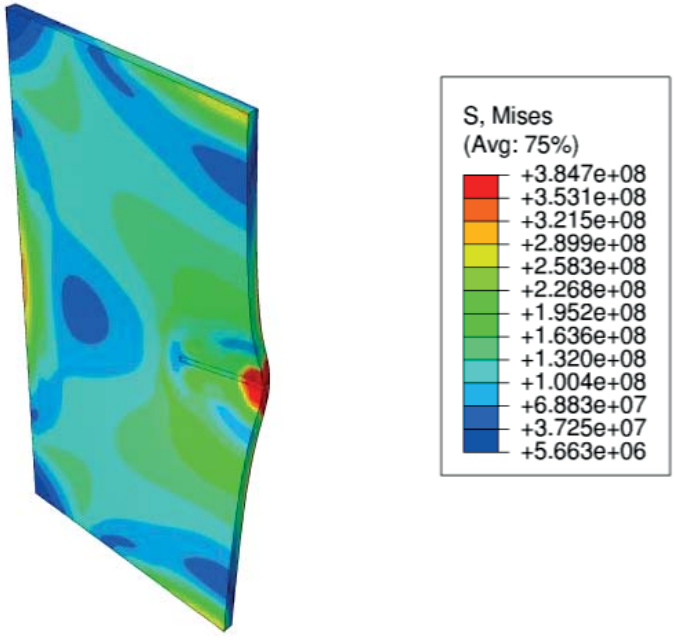

a) $\mathrm{E}=50 \mathrm{~J}$
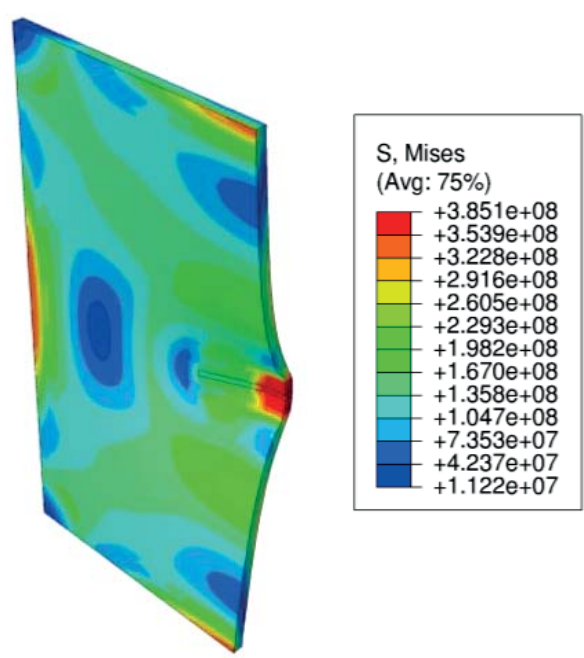

b) $\mathrm{E}=100 \mathrm{~J}$
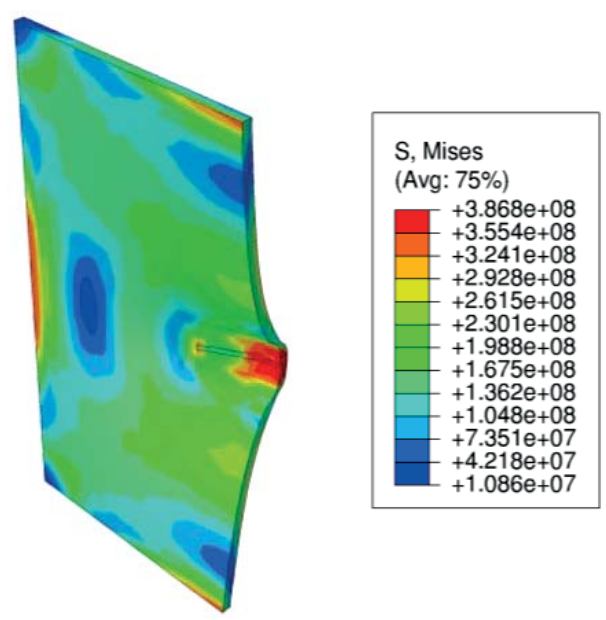

c) $\mathrm{E}=150 \mathrm{~J}$

Figure 5. The effect the impact energy level on the stress distribution of the nothced metal plate with composite circular patch .

Figure 5 shows the stress distributions of the notched metal plate with circular and rectangular composite patches for the present impact energies. Composite circular and rectangular patches prevented perforation of the notched plates 
with increasing impact energy and also stress levels of composite circular and rectangular patches remain same nearly with increasing impact energy. Deformation types are related with composite patch geometry as shown in Figure 5. The patch geometry as a rectangular geometry is more significant from circular geometry. Because deformation area is smaller than circular geometry and the stress levels is also.

\section{Conclusion}

This study addresses the low velocity impact response of repaired notched plates with composite patch for different composite patch geometries and impact energies. The temporal variations of contact force, kinetic energies and the stress distributions of notched plates repaired with composite patch were determined numerically. The results of using the composite patch were also significant in terms of impact resistance. The Johnson-Cook material model was implemented for modelling notched plates. Composite patches were modeled using continuum shell element with orthotropic elastic material model and Hashin damage initiation criterion using composite lay-up technique in available Abaqus/Explicit. Increasing impact energy resulted in the contact force levels to increase whereas the total contact durations decrease. The minimum peak contact forces appeared for the model with notched plate without composite patch. But the maximum peak contact forces appeared for the model with repaired notched plate with circular patch. The notched metal without patch could absorb more much impact energy, however these plates were perforated in the impact energy levels of 100 and $150 \mathrm{~J}$. Composite circular and rectangular patches prevented perforation of the notched plates with increasing impact energy and also stress levels of composite circular and rectangular patches remain same nearly with increasing impact energy.

\section{Acknowledgements}

Authors would like to thank for the financial support of The Scientific and Technological Research Council of Turkey (TUBITAK) under the contract: 216M519.

\section{References}

Mall, S. and Conley, D.S. (2009). Modeling and validation of composite patch repair to cracked thick and thin metallic panels. Composites: Part A, 40, 1331-1339. https://doi.org/10.1016/j.compositesa.2008.08.007.

Shams, S.S. and El-Hajjar, R.F. (2013). Overlay patch repair of scratch damage in carbon fiber/epoxy laminated composites. Composites: Part A, 49, 148-156, https://doi.org/10.1016/j.compositesa.2013.03.005.

Albedah, A., Khan, S.M.A., Benyahia, F. and Bouiadjra, B.B. (2016). Effect of load amplitude change on the fatigue life of cracked Al plate repaired with composite patch. International Journal of Fatigue, 88, 1-9, https://doi.org/10.1016/j.jifatigue.2016.03.002.

Cheng, P., Gong, X.J., Aivazzadeh, S. and Xiao, X. (2014). Experimental observation of tensile behavior of patch repaired composites. Polymer Testing, 34, 146-154, https://doi.org/10.1016/j.polymertesting.2014.01.007.

Constantin, N., Sandu, M. and Sorohan, Ş. (2013). Restoration of the mechanical performance of damaged Al panels using bonded composite repair patches. International Journal of Adhesion \& Adhesives, 42, 69-76, https://doi.org/10.1016/j.ijadhadh.2013.01.003.

Errouane, H., Sereir, Z. and Chateauneuf, A. (2014). Numerical model for optimal design of composite patch repair of cracked aluminum plates under tension. International Journal of Adhesion \& Adhesives, 49, 64-72, https://doi.org/10.1016/j.ijadhadh.2013.12.004 .

Benyahia, F., Aminallah, L., Albedah, A., Bouiadjra, B.B. and Achour, T. (2015). Experimental and numerical analysis of bonded composite patch repair in aluminum alloy 7075 T6. Materials and Design, 73, 67-73, https://doi.org/10.1016/j.matdes.2015.02.009. 
Sabelkin, V., Mall, S., Hansen, M.A., Vandawaker, R.M. and Derriso, M. (2007). Investigation into cracked aluminum plate repaired with bonded composite patch. Composite Structures, 79, 55-66, https://doi.org/10.1016/j.compstruct.2005.11.028.

ABAQUS/Explicit (Version 6.14), User's manual, Finite Element Software. Available from: http://www.simulia. com.

Manes, A., Serpellini, F., Pagani, M., Saponara, M. and Giglio, M. (2014). Perforation and penetration of aluminium target plates by armour piercing bullets. International Journal of Impact Engineering, 69, 39-54, https://doi.org/10.1016/j.ijimpeng.2014.02.010.

Singh, H., Namala, K. K. and Mahajan, P. (2015). A damage evolution study of E-glass/epoxy composite under low velocity impact. Composites Part B,76, 235-248, https://doi.org/10.1016/j.compositesb.2015.02.016. 